\title{
Diagnosis and treatment of pediatric frontotemporal pits: report of 2 cases
}

\author{
Morgan Bliss, MD, ${ }^{1}$ Gerald Grant, MD, ${ }^{2}$ Ethan Tittler, MD, ${ }^{3}$ Tina Loven, DO, ${ }^{2}$ Kristen W. Yeom, MD, ${ }^{4}$ \\ and Douglas Sidell, MD'
}

Departments of ${ }^{1}$ Otolaryngology-Head and Neck Surgery, ${ }^{2}$ Neurosurgery, ${ }^{3}$ Ophthalmology-Oculoplastic and Orbital Surgery, and ${ }^{4}$ Radiology, Stanford University, Stanford, California

\begin{abstract}
In contrast to more common nasal and cervical lesions, the frontotemporal pit is a rarely encountered lesion that is often associated with a dermoid and may track intracranially. Due to delays in diagnosis, the propensity to spread intracranially, and the risk of infection, awareness of these lesions and appropriate diagnosis and management are important. The authors present 2 cases of frontotemporal pits from a single institution. Epidemiology, presentation, and management recommendations are discussed.
\end{abstract}

http://thejns.org/doi/abs/10.3171/2016.5.PEDS1687

KEY WORDS frontotemporal pit; dermoid; intracranial; craniofacial

$\mathrm{P}$ RESENTING features of preauricular pits, branchial cleft anomalies, and nasal dermoids are well described, as are their infectious sequelae. In contrast to these more common lesions, the frontotemporal pit is rarely encountered, and may be either disregarded or misdiagnosed on examination. Due to their ability to track intracranially, involve the dura mater, and have infectious complications, early recognition is imperative. In this report we describe the evaluation and management of frontotemporal pits in 2 pediatric patients treated at our institution, and focus our discussion on diagnostic and management considerations. Detailed radiological and intraoperative images are provided, and a review of the literature is performed.

\section{Case Reports}

\section{Case 1}

History and Examination

A 3-year-old girl was referred to the otolaryngology clinic with a 1-month history of intermittent right periorbital cellulitis that was refractory to multiple courses of oral antibiotics and was initially considered to be an orbital complication of sinusitis. The periorbital swelling was associated with intermittent temporal edema. On further questioning, the patient described incidental mucopurulent drainage from a congenital frontotemporal pit that occurred in concert with her periorbital swelling (Fig. 1).
Imaging

A CT scan was performed and showed a well-circumscribed hypodense lesion in the lateral orbital wall within the greater wing of the sphenoid bone (Fig. 2). The preoperative MRI studies were concerning for mild enhancement of adjacent dura and periorbita (Fig. 3) and also confirmed the communication between the cutaneous frontotemporal pit and a deeper intraosseous lesion. The patient was diagnosed with cellulitis and orbital osteomyelitis associated with an intradiploic dermoid cyst, and was started on broad-spectrum intravenous (IV) antibiotics.

\section{Operation}

After completing a 3-week course of IV antibiotics with only modest improvement, the patient was taken to the operating room for excision of the sinus tract and dermoid cyst by a multidisciplinary team of surgeons including Ear, Nose, and Throat; Neurosurgery; and Oculoplastics. The lesion was approached via a hemicoronal incision with interfascial temporalis takedown, excision of diseased orbitozygomatic bone, and frontal craniotomy. The dermoid sinus tract was found to be adherent to the dura; however, the dura was not traversed. The periorbita remained intact. The frontotemporal cutaneous tract was separated from the intraosseous cyst where it entered the bone (Fig. 4), and the skin surrounding the external os was removed in an elliptical excision. A titanium mesh implant was placed to reconstruct the temporal fossa (Fig. 5).

ABBREVIATIONS IV = intravenous. 


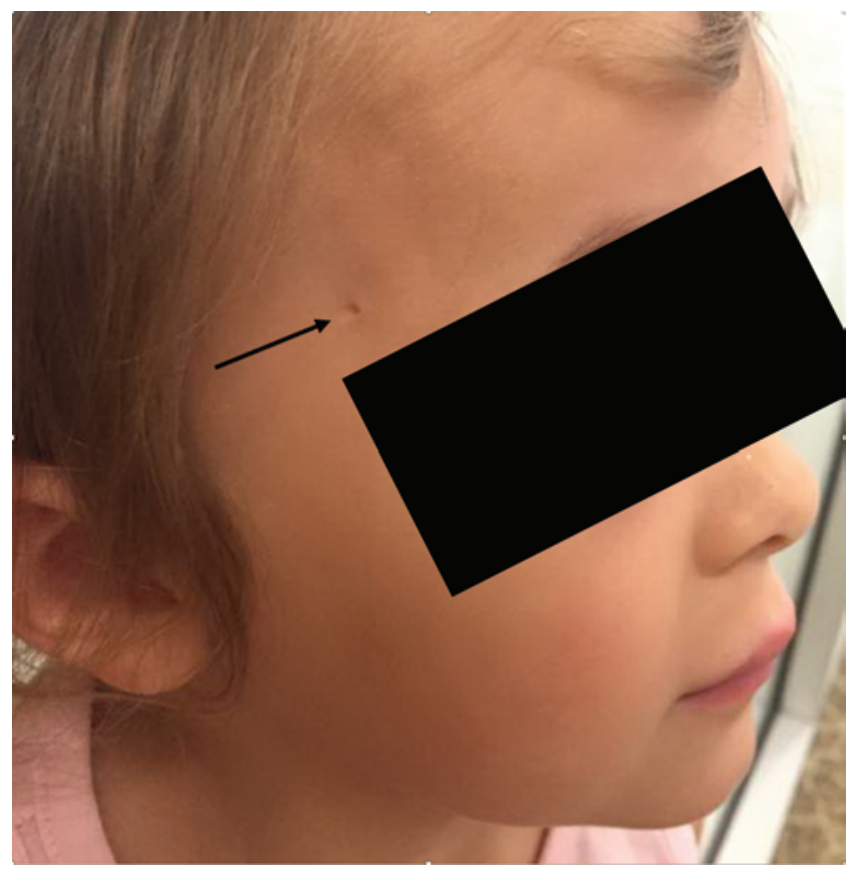

FIG. 1. Case 1. Photograph of the right frontotemporal pit (arrow). Figure is available in color online only.

\section{Pathological Findings and Postoperative Course}

Histopathological analysis confirmed the presence of a dermoid tumor and dermal sinus tract, with cutaneous extension to the temporal pit. The patient's postoperative course was complicated by fevers, neutropenia, constipation, and transient paresis of the frontal branch of the right facial nerve. Cultures from the surgical specimens grew multiple anaerobic organisms: Peptostreptococcus, Streptococcus, Finegoldia, Peptoniphilus, Anaerococcus, and Porphyromonas somerae, as well as multiple other anaerobic gram-positive cocci that were unable to be identified. By postoperative Week 6 , the patient's infection had resolved, she had regained function of the frontal branch

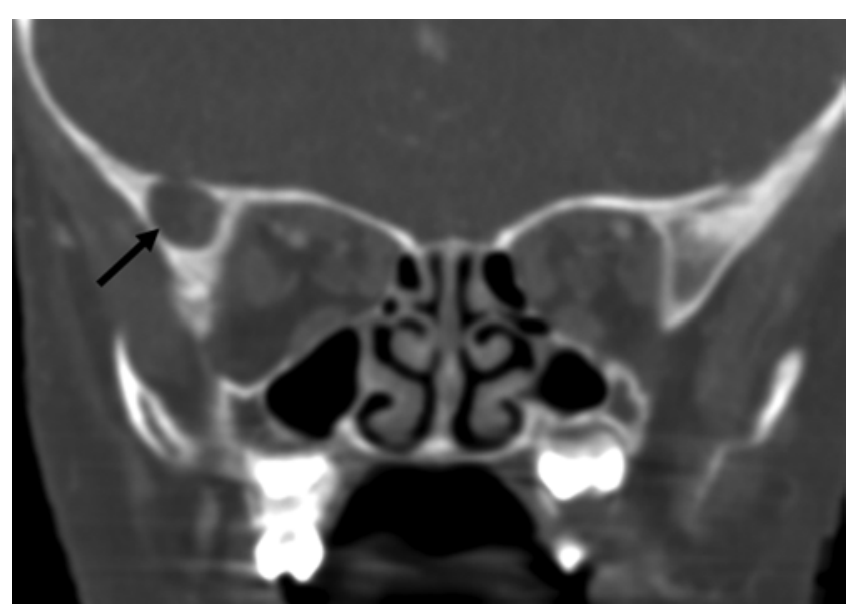

FIG. 2. Case 1. Coronal CT scan obtained with contrast demonstrating a well-circumscribed, lucent bone lesion (arrow) within the greater wing of the sphenoid, in the lateral orbital wall on the right side.

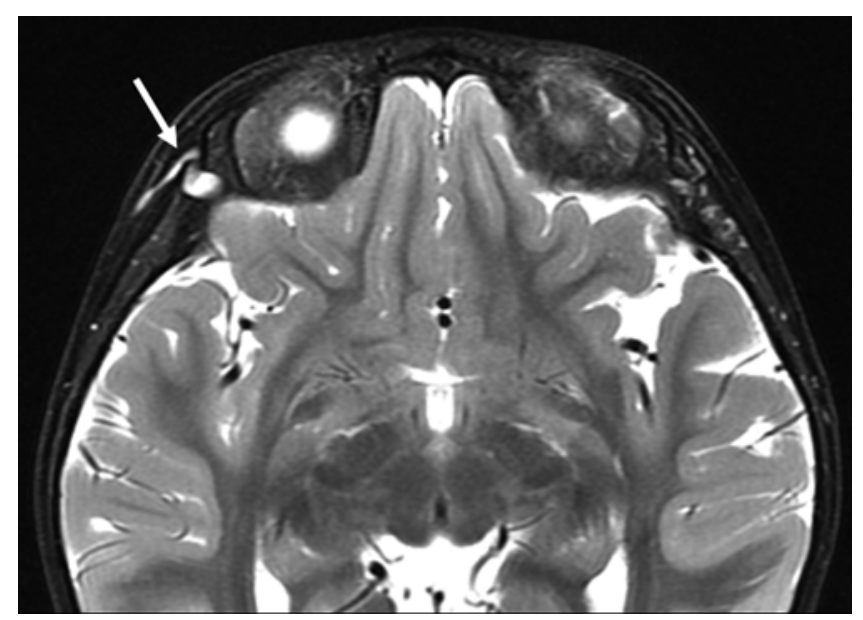

FIG. 3. Case 1. Axial MR image (T2-weighted image with fat suppression) demonstrating abnormal signal associated with inflammatory soft tissue adjacent to the intraosseous dermoid cyst of the lateral orbital wall on the right side (arrow).

of the right facial nerve, and she had no recurrence of inflammation of the right temporal region.

\section{Case 2}

History

A 2-year-old boy presented to the otolaryngology clinic with a right frontotemporal pit that drained clear yellow fluid and was associated with intermittent swelling of the ipsilateral periorbital region.

\section{Imaging}

An MRI study demonstrated a sinus tract that was associated with a mass in the sphenoid buttress and appeared to extend to the frontozygomatic suture without evidence of intracranial or dural involvement.

\section{Management}

The patient's family elected to observe the lesion without any surgical intervention. The patient was followed

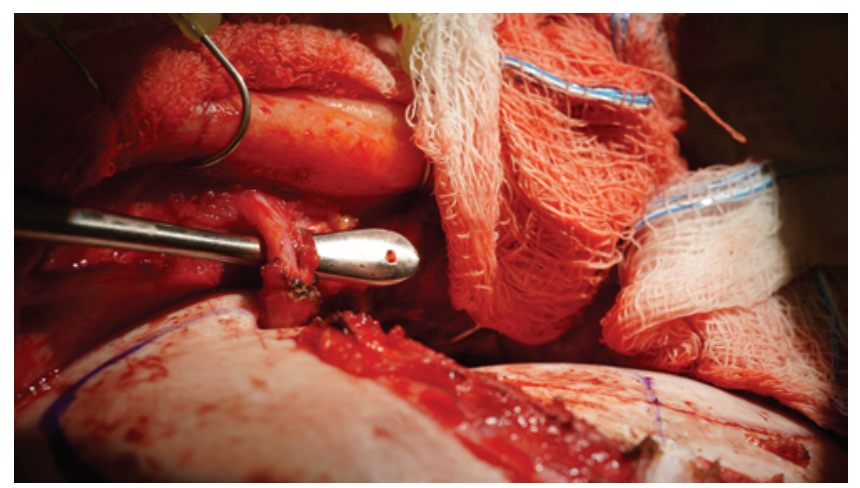

FIG. 4. Case 1. Intraoperative view looking inferiorly at the sinus tract connecting the cutaneous frontotemporal pit to the intraosseous cyst within the lateral wall of the right orbit. The metal probe is seen passing behind the sinus tract and the frontozygomatic suture is marked with purple ink. Figure is available in color online only. 


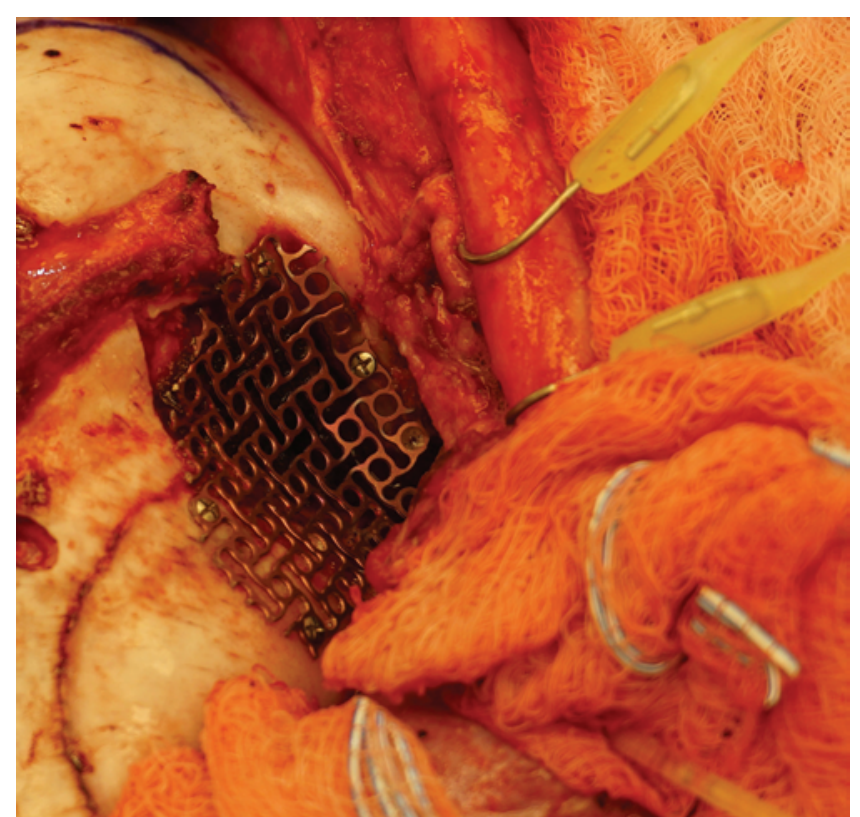

FIG. 5. Case 1. Intraoperative photograph showing the titanium mesh overlying the temporal fossa defect. Figure is available in color online only. clinically and ultimately his care was transferred to a different institution. He was free of complications at his most recent visit.

\section{Discussion}

Dermoid cysts are the result of ectodermal rests that become sequestered during closure of the neural tube. They are frequently identified at cranial suture lines, and rarely involve dura at the frontotemporal location. When compared with glabellar dermoids, frontotemporal lesions are rare, and an optimal diagnosis and management pathway has not been established. ${ }^{6,9}$ In this report, we describe 2 congenital frontotemporal dermoids and the management of each lesion.

In the largest series to date, Bonavolontà et al. describe 145 patients with orbital dermoids. Of these, 1 patient $(0.7 \%)$ had an associated lateral lesion with a frontotemporal sinus tract. ${ }^{2}$ Including the cases presented herein, fewer than 8 patients with intracranial extension associated with a frontotemporal pit have been reported (Table 1). ${ }^{3-5,8-10}$ The median age at diagnosis in these cases was 2.5 years (range 9 months -6 years). Of the patients without intracranial extension, there appears to be an older median age at diagnosis ( 5 years; range 20 months -56 years) than those with dural involvement, possibly due to the more isolated nature of the lesion. ${ }^{1,2,5,6}$

Independent of age, the most common complaint bringing patients with frontotemporal pits to medical attention

TABLE 1. Presentation and management of patients with frontotemporal pits and dural involvement

\begin{tabular}{|c|c|c|c|c|c|}
\hline $\begin{array}{l}\text { Authors \& } \\
\text { Year }\end{array}$ & $\begin{array}{l}\text { Patient } \\
\text { Age }\end{array}$ & Presentation & Imaging & Management & Outcome \\
\hline $\begin{array}{l}\text { Green, } \\
1973\end{array}$ & 6 yrs & $\begin{array}{l}\text { Rt temporal scab noted at birth. Mass } \\
\text { enlarged at } 2 \text { yrs of age. }\end{array}$ & Radiograph & $\begin{array}{l}\text { Direct excision w/ removal to outer table of } \\
\text { cranium. }\end{array}$ & $\begin{array}{l}\text { No recurrence at 9-mo } \\
\text { follow-up. }\end{array}$ \\
\hline $\begin{array}{l}\text { Cullen, } \\
1974\end{array}$ & $2 \mathrm{yrs}$ & $\begin{array}{l}\text { Inflamed outer canthus, treated as } \\
\text { inflamed tarsal cyst w/ antibiotics. } \\
\text { Re-presented w/ rt temple lesion pit. }\end{array}$ & Radiograph & $\begin{array}{l}\text { Rt frontotemporal craniotomy, dural eleva- } \\
\text { tion, complete excision of cyst. Dura } \\
\text { excised w/ cyst \& tract. }\end{array}$ & Not discussed. \\
\hline Hong, 1998 & $2 \mathrm{yrs}$ & $\begin{array}{l}\text { Recurrent discharge, right fronto- } \\
\text { temporal region. No evidence of } \\
\text { infection. }\end{array}$ & Postop CT & $\begin{array}{l}\text { Direct elliptical excision w/ frontotemporal } \\
\text { craniotomy. Lesion excised from dura; } \\
\text { dura left intact. }\end{array}$ & $\begin{array}{l}\text { Uneventful recovery. No } \\
\text { complications. Follow-up } \\
\text { duration not discussed. }\end{array}$ \\
\hline $\begin{array}{l}\text { Parag et } \\
\text { al., } 2001\end{array}$ & $1 \mathrm{yr}$ & $\begin{array}{l}\text { Lt temporal mass w/ painful enlarge- } \\
\text { ment \& orbital swelling. Three } \\
\text { discharging sinuses were present } \\
\text { (ipsilat cheek, lower eyelid, tempo- } \\
\text { ral region). }\end{array}$ & CT & $\begin{array}{l}\text { Hemicoronal approach, lateral orbitotomy, } \\
\text { dissection to dura via temporal defect. } \\
\text { Complete excision of tract, cyst, \& ramifi- } \\
\text { cations of the cyst performed. }\end{array}$ & $\begin{array}{l}\text { Well-healed incision. No } \\
\text { recurrence at 3-mo } \\
\text { follow-up. }\end{array}$ \\
\hline $\begin{array}{l}\text { Wells \& } \\
\text { Harris, } \\
2004\end{array}$ & $9 \mathrm{mos}$ & $\begin{array}{l}\text { Fever, It periorbital edema, congenital } \\
\text { lesion above It eyebrow. }\end{array}$ & CT & $\begin{array}{l}\text { Eyelid crease incision, subperiosteal dissec- } \\
\text { tion, anterior orbitotomy. Contingent frontal } \\
\text { craniotomy planned but not needed. Dis- } \\
\text { section carried through defect in greater } \\
\text { sphenoid wing \& into middle cranial fossa. } \\
\text { Separated from dura w/o disruption. }\end{array}$ & $\begin{array}{l}\text { No clinical or CT evidence } \\
\text { of recurrence at 7-mo } \\
\text { follow-up. }\end{array}$ \\
\hline $\begin{array}{r}\text { Scolozzi et } \\
\text { al., } 2005\end{array}$ & $1 \mathrm{yr}$ & Inflamed cutaneous sinus. & $\begin{array}{l}\text { MRI \& CT } \\
\text { (follow- } \\
\text { ing initial } \\
\text { excision) }\end{array}$ & $\begin{array}{l}\text { Superficial incomplete excision performed. } \\
\text { Imaging subsequently obtained. Lesion } \\
\text { then excised via coronal approach, lateral } \\
\text { orbitotomy; complete excision achieved. }\end{array}$ & $\begin{array}{l}\text { No complications. Com- } \\
\text { plete recovery at 8-mo } \\
\text { follow-up after complete } \\
\text { excision. }\end{array}$ \\
\hline $\begin{array}{l}\text { Present } \\
\text { study* }\end{array}$ & 3 yrs & $\begin{array}{l}\text { Periorbital cellulitis w/ intermittent } \\
\text { mucopurulent drainage. }\end{array}$ & CT \& MRI & $\begin{array}{l}\text { Hemicoronal approach, interfascial tempora- } \\
\text { lis takedown, excision of diseased orbito- } \\
\text { zygomatic bone, \& frontal craniotomy. }\end{array}$ & $\begin{array}{l}\text { No clinical or MRI evidence } \\
\text { of recurrence at 5-mo } \\
\text { follow-up. }\end{array}$ \\
\hline
\end{tabular}

\footnotetext{
* The second case is not included because there was no intracranial extension.
} 
is recurrent drainage, both with and without the presence of infection, followed by the presence of a temporal mass associated with the pit. Unfortunately, these findings alone do not appear to be predictive of intracranial extension. ${ }^{1,4-10}$ When considering infection, there have been no reported cases of meningitis associated with frontotemporal pits, regardless of intracranial involvement. In contrast, reports of orbital infections occurring in concert with the sinus tract are described. The 3 -year-old patient described in this report presented with preseptal cellulitis, and required a prolonged course of IV antibiotics for treatment of osteomyelitis. Despite aggressive antibiotic therapy, the infectious process did not resolve until after surgical excision of the tract. Similar findings documented in 2 of the known cases of frontotemporal pits include lateral rectus palsy, persistent fevers, drainage, and swelling, despite treatment with antibiotics. ${ }^{5,10}$

Regardless of the inability to predict extension of the lesion or the risk of infection based on physical examination alone, the recommendation for preoperative imaging of these lesions is also inconsistent among reports. ${ }^{4,7,8}$ Although intracranial involvement has been reported, we were unable to identify any reports of intradural extension in the literature, and excision in the absence of imaging has been described, with good results. Nevertheless, we still believe that MRI and CT scanning allow one to quantify the extent of inflammation, and to identify the presence of osseous involvement, intracranial extension, and/ or orbital extension. We thus believe that imaging provides information that is of value both for preoperative planning purposes and for better counseling of patients and their families with regard to the extent of each lesion and surrounding inflammation.

For any lesion with intracranial and orbital involvement, a multidisciplinary approach involving neurosurgery, ophthalmology, and otolaryngology is recommended. A coronal approach provides a large area of exposure with an acceptable cosmetic outcome. This was performed in the patient in Case 1 due to the extent of osteomyelitis and the position of the tract in relation to the facial nerve. Direct excision of the tract is an alternative approach with the advantage of reducing incision size. It is a viable option if adequate exposure is achieved to perform a safe and complete excision. ${ }^{1,4-6}$ Because the trajectory of the tract often puts the patient at risk for injury of the frontal branch of the facial nerve, this should be taken into consideration when choosing the approach for each lesion as it was for the patient in Case 1. As was proven for the first patient described herein, excision of the entire sinus tract to the level of dural attachment appears to be an effective way of preventing recurrence while also reducing the undue risk of a postoperative CSF leak. Following truncation of the lesion at the level of the dura, the small amount of adherent tract can be marsupialized and cauterized without an appreciable risk of recurrence. With regard to reconstruction in this particular case, we used titanium mesh as a scaffold to support the temporalis muscle over the sphenoid defect. This prevents a potential cosmetic concern when the muscle sinks into the defect, otherwise known as "temporal hollow." In our collective experience in using titanium mesh at this institution, we have not appreciated any long-term complications or need for revision in the pediatric population.

\section{Conclusions}

Frontotemporal pits with associated dermoids are rare. Although children may appear to present at a younger age when there is intracranial involvement, the risk of infection and the extent of inflammation is difficult to ascertain based solely on history and physical examination. Patients are at risk for periorbital infection regardless of the presence or absence of intracranial extension, and infection may be recalcitrant to IV antibiotics until excision is performed. The workup of children with frontotemporal pits should include MRI with or without CT scanning. All patients should have a multidisciplinary team for surgical management.

\section{References}

1. Bartlett SP, Lin KY, Grossman R, Katowitz J: The surgical management of orbitofacial dermoids in the pediatric patient. Plast Reconstr Surg 91:1208-1215, 1993

2. Bonavolontà G, Tranfa F, de Conciliiis C, Strianese D: Dermoid cysts: 16-year survey. Ophthal Plast Reconstr Surg 11:187-192, 1995

3. Cullen JF: Orbital diploic dermoids. Br J Ophthalmol 58:105-106, 1974

4. Green MF: A lateral dermal sinus associated with an intradiploic cyst. Br J Plast Surg 26:298-300, 1973

5. Hong SW: Deep frontotemporal dermoid cyst presenting as a discharging sinus: a case report and review of literature. Br J Plast Surg 51:255-257, 1998

6. Hönig JF: A de novo discharging sinus of the fronto-orbital suture: a rare presentation of a dermoid cyst. J Craniofac Surg 9:536-538, 1998

7. Lacey M, Gear AJL, Lee A: Temporal dermoids: three cases and a modified treatment algorithm. Ann Plast Surg 51:103-109, 2003

8. Parag P, Prakash PJ, Zachariah N: Temporal dermoid-an unusual presentation. Pediatr Surg Int 17:77-79, 2001

9. Scolozzi P, Lombardi T, Jaques B: Congenital intracranial frontotemporal dermoid cyst presenting as a cutaneous fistula. Head Neck 27:429-432, 2005

10. Wells TS, Harris GJ: Orbital dermoid cyst and sinus tract presenting with acute infection. Ophthal Plast Reconstr Surg 20:465-467, 2004

\section{Disclosures}

The authors report no conflict of interest concerning the materials or methods used in this study or the findings specified in this paper.

\section{Author Contributions}

Conception and design: Bliss, Grant, Tittler. Acquisition of data: Grant, Yeom. Drafting the article: Sidell, Bliss, Loven. Critically revising the article: Sidell, Bliss, Grant, Tittler, Loven. Reviewed submitted version of manuscript: Bliss. Approved the final version of the manuscript on behalf of all authors: Sidell. Administrative/technical/material support: Sidell, Grant, Yeom. Study supervision: Sidell.

\section{Correspondence}

Douglas Sidell, Department of Otolaryngology-Head and Neck Surgery, Stanford University, 801 Welch Rd., Stanford, CA 94305. email: dsidell@stanford.edu. 